\title{
Deletion Mutations in an Australian Series of HNPCC Patients
}

\author{
Mary McPhillips', Cliff J. Meldrum', Rhona Creegan², Edward Edkins', Rodney J. Scott ${ }^{1,3}$ \\ IDivision of Genetics, Hunter Area Pathology Service, John Hunter Hospital, Lookout Road, New Lambton, NSW 2305 Australia; 2Princess Margaret Children's Hospital, \\ Perth, WA 6000 Australia; ${ }^{3}$ Discipline of Medical Genetics, School of Biomedical Sciences, Faculty of Health, University of Newcastle and the Hunter Medical Research \\ Institute, Newcastle NSW 2308, Australia
}

Key words: HNPCC, deletion mutations, multiplex ligation-dependent probe amplification assay

Corresponding author: Rodney J.Scott, e-mail: rodney.scott@newcastle.edu.au

Submitted: 15 November 2004

Accepted: 30 November 2004

\begin{abstract}
Hereditary non polyposis colorectal cancer (HNPCC) is characterized by the presence of early onset colorectal cancer and other epithelial malignancies. The genetic basis of HNPCC is a deficiency in DNA mismatch repair, which manifests itself as DNA microsatellite instability in tumours. There are four genes involved in DNA mismatch repair that have been linked to HNPCC; these include hMSH2, hMLH1, hMSH6 and hPMS2. Of these four genes hMLH1 and hMSH2 account for the majority of families diagnosed with the disease. Notwithstanding, up to 40 percent of families do not appear to harbour a change in either hMSH2 or hMLH1 that can be detected using standard screening procedures such as direct DNA sequencing or a variety of methods all based on a heteroduplex analysis.

In this report we have screened a series of 118 probands that all have the clinical diagnosis of HNPCC for medium to large deletions by the Multiplex Ligation-Dependent Probe Amplification assay (MLPA) to determine the frequency of this type of mutation. The results indicate that a significant proportion of Australian HNPCC patients harbour deletion or duplication mutations primarily in $\mathrm{hMSH} 2$ but also in $\mathrm{hMLH}$.
\end{abstract}

\section{Introduction}

Hereditary non polyposis colorectal cancer (HNPCC; MIM 120435 and 120436) is an autosomal dominantly inherited disorder that predisposes males to an approximate colorectal cancer risk of $80 \%$ by 70 years of age and females to a $40 \%$ risk of bowel cancer and a $40 \%$ risk of endometrial cancer by the same age [1]. The genetic basis of HNPCC has been linked to errors in DNA mismatch repair [2-5], which leaves a characteristic tumour signature of DNA microsatellite instability (MSI) that can be used as a surrogate marker for this syndrome $[6,7]$.

At least four genes have been associated with DNA mismatch repair and HNPCC and are hMSH2,
hMLH1, hMSH6 and hPMS2; for review see Papadopoulos and Lindblom [8]. Both hMSH2 and hMLH1 account for somewhere between $50 \%$ and $60 \%$ of all families that adhere to the Amsterdam Criteria (3 relatives with colorectal cancer (CRC); one must be a first degree relative of the other two; cross at least two generations; CRC must be diagnosed in one relative under the age of 50 years and familial adenomatous polyposis (FAP) must be excluded). Somewhere between $2 \%$ and $20 \%$ of HNPCC families defined by the Bethesda Criteria (excluding the Amsterdam Criteria families) are associated with mutations in these two genes [9-12]. The contribution of hPMS2 and hMSH6 remains undefined, however, on current evidence both hPMS2 and hMSH6 appear 
to account for approximately $5 \%$ of all HNPCC families $[13,14]$.

The remaining $30-40 \%$ of Amsterdam Criteria families that do not evidently harbour germline mutations in the genes described either contain exonic or whole gene deletions, cryptic alterations within their coding regions, harbour changes in promoter/enhancer regions or are due to other genes that await identification [8]. The diagnosis of HNPCC families remains problematic for a variety of reasons despite knowledge about the genetic basis of the disease.

The majority of mutations identified to date are determined by genetic amplification strategies using the polymerase chain reaction and thereafter, subsequent analyses of the amplified product. This strategy has been extremely valuable in identifying a large number of mutations that can be clearly associated with disease development. This approach, however, does not identify inframe deletions that potentially remove whole exons or the entire gene nor does it recognise duplications that are capable of either introducing premature stop codons or inserting transcribable coding sequence that culminates in the insertion of nonsense peptide which alters the functional properties of the protein.

Using a new approach, known as multiplex ligation-dependent probe amplification (MLPA), deletion changes can now readily be identified [15]. In this report we have screened 118 probands who either came from families that adhered to the Amsterdam or Bethesda criteria for whole gene or exon deletions in hMLH1 and hMSH2. Our results indicate that hMSH2 deletions are much more frequent in the Australian population compared to $\mathrm{hMLH} 1$ deletions and that MLPA is a useful aid in identifying smaller deletions that occur in the proximity of the splice donor and acceptor sites within hMSH2 and hMLH1.

\section{Materials and methods}

\section{Patients and samples}

All patients enrolled in this study have signed an informed consent document for genetic testing. The patients were from the State of New South Wales or Western Australia, which has a total population of approximately 9 million inhabitants. The centre where the genetic testing was undertaken is a statewide service, which also includes the Australian Capitol Territory.

Patients selected for MLPA testing had been previously diagnosed with cancer and had tested negative for point mutations in hMLH1 or hMSH2 by DGGE or DHPLC analysis. The majority of patients had obtained a positive result for immunohistochemistry staining (i.e. displayed absence of staining for either hMSH2 or hMLH1) and were considered to be prime candidates to harbour deletions within the respective gene. All families fulfilled the diagnostic criteria of HNPCC by adhering to either the Amsterdam 1 or 2 Criteria.

\section{DNA extraction}

All experiments were performed on genomic DNA extracted from blood lymphocytes. DNA was isolated from whole blood using the method described by Miller et al [16] (1988) without modification.

\section{MLPA reaction}

A Multiplex Ligation-Dependent Probe Amplification (MLPA) kit was obtained from MRC-Holland, Amsterdam, the Netherlands. The MLPA method was developed by Schouten et al [15] and uses a probe mixture containing 16 probe pairs for $\mathrm{hMSH} 2$ and 19 probe pairs for hMLH1 plus 7 control probe pairs. Initially $250 \mathrm{ng}$ of genomic DNA in $5 \mu \mathrm{l}$ of TE was heated to $95^{\circ} \mathrm{C}$ for 5 minutes and allowed to cool to $25^{\circ} \mathrm{C}$ before addition of the hMLH1 and hMSH2 probe mixture and buffer. The solution was reheated to $95^{\circ} \mathrm{C}$ for 5 minutes followed by overnight hybridisation of the probe at $60^{\circ} \mathrm{C}$. The mixture was cooled to $54^{\circ} \mathrm{C}$ before DNA ligase and buffer were added, followed by ligation at $54^{\circ} \mathrm{C}$ for 15 minutes and inactivation of the ligase at $98^{\circ} \mathrm{C}$ for 5 minutes. The ligation products were then amplified with one unlabelled and one FAM-labelled primer using the thermal cycling conditions advised by the manufacturer. Following amplification, $0.75 \mu \mathrm{l}$ of the PCR reaction, $0.75 \mu \mathrm{l}$ of deionised water, $0.5 \mu \mathrm{l}$ of an internal standard (TAMRA-500) and $12 \mu \mathrm{l}$ of deionised formamide were mixed and incubated at $94^{\circ} \mathrm{C}$ for 2 minutes. The samples were then analysed on an Applied Biosystems 310 capillary sequencer with a $47-\mathrm{cm}$ capillary and POP4 Genescan polymer. Data for the peak area were exported to an Excel spreadsheet. All peak areas were normalised by dividing each peak area by the combined peak areas of all peaks in that lane. The normalised peak area was then divided by the average normalised peak area of that probe amplification product of all samples. Deletion of an exon for an allele is indicated by the reduction in a relative peak area for that probe amplification product of $30 \%$, while duplication is indicated by an increase in the peak area by $30 \%$.

\section{DNA sequencing}

All single exon deletions were subject to DNA sequencing to determine whether mutations occurred 
within the MLPA probe binding regions, thereby presenting as an apparent exon deletion. DNA sequencing was performed on a semi-automated sequencing unit (model 310, Perkin-Elmer Applied Biosystems Division, Foster City, CA) according to the manufacturer's instructions.

\section{Results}

The majority of patients enrolled in this study had had their tumours assessed for the presence or absence of hMLH1 or hMSH2 and this information was used as a guide to examine in detail which gene was most likely to harbour a deletion or duplication. In those instances where no knowledge was available about the offending DNA mismatch repair gene then both genes were interrogated with equal emphasis.

From a total number of patients 18 index cases were identified as having either a deletion or duplication in hMSH2 or hMLH1. By far the greatest proportion of confirmed exonic deletions (11) were identified in hMSH2 ( $61 \%)$ with only 2 exonic deletions being identified in hMLH1 ( 1 1\%). Two duplications were observed, one in $\mathrm{hMSH} 2$ and the other in $\mathrm{hMLH} 1$.

Two apparent exonic deletions were also identified by MLPA, which were due to a 2 base pair deletion (1706-1707delAA) in hMSH2 and a 5 base pair deletion (728-732delATGGT) in hMLH1, respectively. These two changes occurred within the annealing sites of the respective probes used for the assay. A third potential deletion was observed in exon 16 of hMSH2 which could not be readily confirmed by virtue of there being no easily identifiable method of determining the $3^{\prime}$ end of the deletion. Similar to the other two apparent deletions a mutation was identified at position 2635, which was a substitution (C>G) that was within the annealing site of exon 16 MPLA probe.

Two duplications were identified, one in hMSH2 encompassing exons 9-11 and one in hMLH1 involving exons 4-6. Both of these changes were presumed to disrupt the coding sequence by the introduction of extraneous DNA.

The changes identified in hMSH2 include one whole gene deletion, two probands with exon 8 deleted, eight probands who harboured unique deletions (see Table 1) and one patient that according to MLPA had an exon 15 deletion. This deletion could not be easily confirmed by an alternative method since it occurs in the most $3^{\prime}$ exon of MSH2 and the presumed breakpoint was not readily identifiable.
The two remaining exonic deletions in hMLH1 included a deletion of exons 1 and 2 in one patient and a deletion of exons 7 to 11 in a second unrelated patient.

The disease characteristics of the patients harbouring deletion mutations are shown in Table 1. The majority of patients (83\%) were diagnosed with colorectal cancer under the age of 50 years and there were three patients diagnosed with extra-colonic disease (two endometrial cancers and one ampulla of Vater carcinoma). The family histories of disease were similar to that expected from HNPCC and the average age of confirmed colorectal cancer was 44.8 years, which was not significantly different to patients diagnosed with other types of mutation in either hMSH2 or hMLH1 [17]. There were 101 cases of cancer reported in the families of which 93 could be accurately identified. From the 93 reported cancer cases there were 65 cases of colorectal cancer, 11 cancers of the reproductive tract (both endometrial and ovarian cancers), 6 breast cancer cases, of which four occurred at an unusually early age and an assortment of unusual cancers that have been found to be over-represented in HNPCC families, including cancers of the central nervous system, bile duct, stomach and kidney.

\section{Discussion}

The identification of deletion mutations has traditionally been difficult as it entailed the use of Southern Blotting. Since the introduction of the multiplex ligation-dependent probe amplification assay the identification of deletion and duplication mutations has become considerably easier. Accurate estimates of the frequency of whole exon deletions or duplications in HNPCC can now be addressed and in our experience we believe that these types of mutation may account for up to $15 \%$ of all mutations identified in the Australian HNPCC population. In the population used in this report exonic deletions or duplications of hMSH2 occurred with a significantly greater frequency compared to hMLH1 which is in agreement with the findings of Gille et al [18], Taylor et al [19], Charbonnier et al [20] and Bunyan et al 2004 [21] who identified primarily hMSH2 deletion/duplication mutations.

The MLPA assay appears to be an extremely valuable screening tool prior to a more extensive mutation analysis as it not only identifies exonic deletions/duplications but is also capable of identifying point mutations that lie in the region of probe binding or ligation. When point mutations occur within these regions the resulting dosage appears as an apparent loss of the respective exon. In our experience, if the 
Table 1. Disease characteristics of the 18 families tested by MLPA

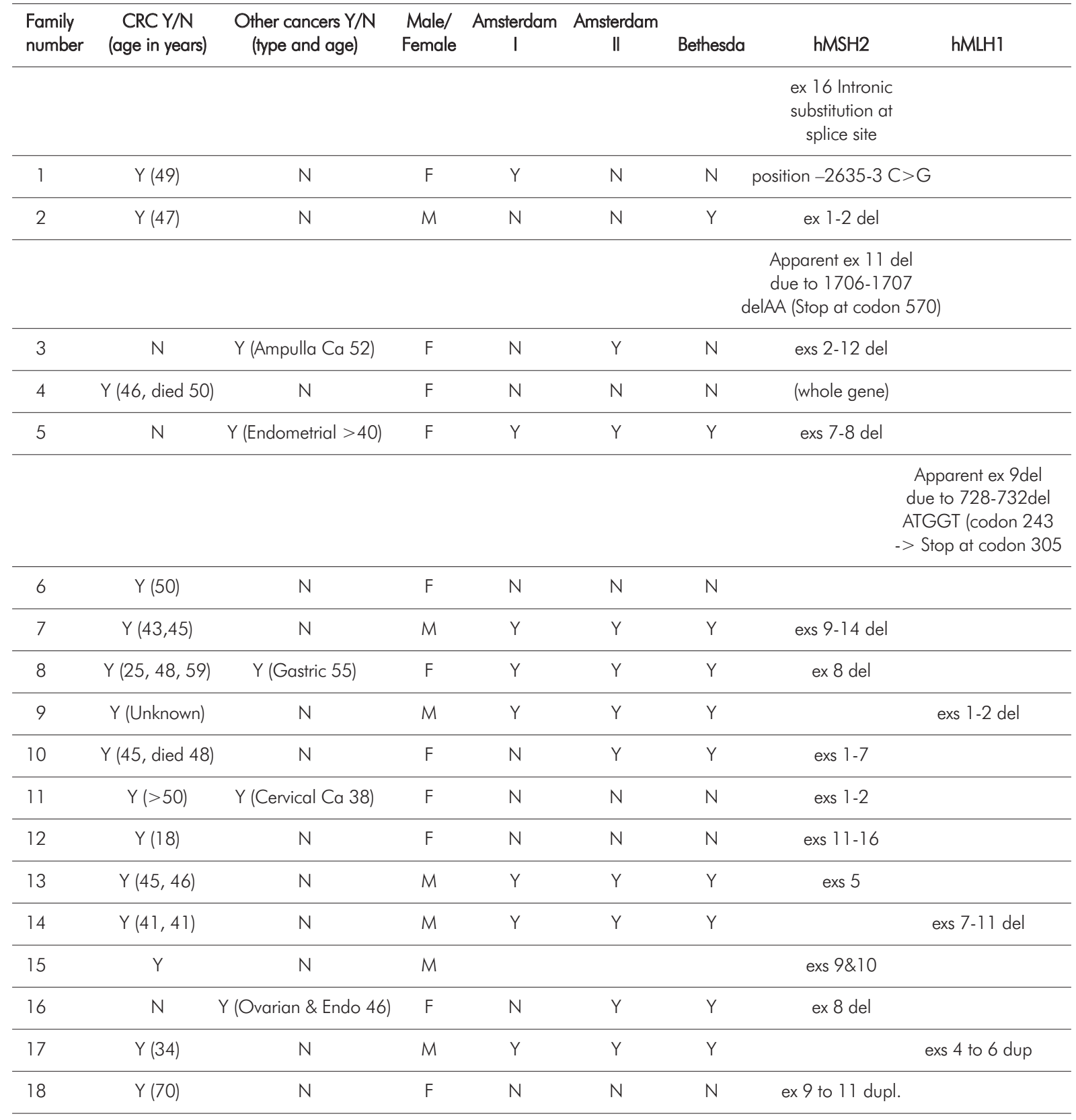

MLPA assay reveals a single exon deletion it should be confirmed by sequencing the entire segment of DNA including both primer-binding sites. By undertaking this strategy we were able to identify small deletions in three patients, which were all deemed to be causative as they were predicted to interfere with exon splicing.

When examining the family profiles of patients harbouring deletion or duplication mutations against families that harboured causative missense or nonsense mutations little difference between the disease characteristics could be observed. In total there were 104 cancers identified in 18 families and the average age of colorectal cancer diagnosis was 44.8 years compared to that observed in our previous study (45.77 years for hMSH2 mutation carriers and 47.16 for hMLH1 mutation carriers). All patients had a family history of disease indicating that these changes were not de novo. In addition to colorectal cancer, there was an over-representation of endometrial cancer (13 cases), followed by CNS tumours (3 cases), renal tract cancers (3) and a variety of other cancers present in 
2 or less patients. Interestingly, breast cancer was also represented in this set of families with an average age of diagnosis being 50 years. Within this group, however, there were two elderly patients; one case was most likely to be a phenocopy (and could not be tested) as she was 82 years of age and the other one who was diagnosed with breast cancer at the age of 70 after having been diagnosed with colorectal cancer at the age of 63 years. All the other cases of breast cancer were diagnosed under the age of 50 years.

There were two duplications identified in this study, one in hMSH2 and the other in hMLH1. There did not appear to be any difference between those families found to harbour duplications in either hMSH2 or hMLH1 compared to families that harboured deletions in either of these genes. The numbers of patients precluded any statistical analysis.

In summary, there does not appear to be any overall difference in the disease profiles observed in families that harbour exonic deletions compared to those that have been shown to be associated with nonsense or causative missense changes. MLPA appears to be an extremely useful screening method that can identify up to $15 \%$ of the mutations that occur in HNPCC families.

\section{References}

1. Watson P and Lynch HT. Extracolonic cancer in hereditary non polyposis colorectal cancer. Cancer 1993; 71: 677-685.

2. Fishel R, Lescoe MK, Rao MRS, Copeland NG, Jenkins NA, Garber J, Kane M and Kolodner R. The human mutator gene homolog MSH2 and its association with hereditary nonpolyposis colon cancer. Cell 1993; 75: 1027-1038.

3. Leach FS, Nicolaides NC, Papadopoulos N, Liu B, Jen J, Parsons R, Peltomaki P, Sistonen P, Aaltonen LA, Nystrom-Lahti M, Guan X-Y, Zhang J, Meltzer PS, Yu J-W, Kao F-T, Chen DJ, Cerosaletti RE, Fournier K, Todds S, Lewis T, Leach RJ, Naylor SL, Weissenbach J, Mecklin J-P, Jarvinen H, Petersen GM, Hamilton SR, Green J, Jass J, Watson P, Lynch HT, Trent JM, de la Chapelle A, Kinzler KW and Vogelstein B. Mutations in a mutS homolog in hereditary nonpolyposis colorectal cancer. Cell 1993; 75: 1215-1225.

4. Bronner CE, Baker SM, Morrison PT, Warren G, Smith LG, Lescoe MK, Kane M, Earabino C, Lipford J, Lindblom A, Tannergard P, Bollag RJ, Godwin AR, Ward DC, Nordenskjold M, Fishel R, Kolodner R and Liskay RM. Mutation in the DNA mismatch repair gene homologue hMLH1 is associated with hereditary nonpolyposis colon cancer. Nature 1994; 368: 258-261.

5. Nicolaides NC, Papadopoulos N, Liu B, Wei Y-F, Carter KC, Ruben SM, Rosen CA, Haseltine WA, Fleischmann RD, Fraser GM, Adams MD, Venter JC, Dunlop MG, Hamilton SR, Petersen GM, de la Chapelle A, Vogelstein B and Kinzler K. Mutations of two PMS homologues in hereditary nonpolyposis colon cancer. Nature 1994; 371: 75-80.

6. Ionov Y, Peinado MA, Malkhosyan S, Shibata D and Perucho M. Ubiquitous somatic mutations in simple repeated sequences reveal a new mechanism for colonic carcinogenesis. Nature 1993; 363: 558-561.
7. Thibodeau SN, Bren G and Schaid D. Microsatellite instability in cancer of the proximal colon. Science 1993; 260: 816-819.

8. Papadopoulos N and Lindblom A. Molecular basis of HNPCC: mutations of MMR genes. Hum Mutat 1997; 10: 89-99.

9. Buerstedde JM, Alday P, Torhorst J, Weber W, Muller H and Scott R. Detection of new mutations in six out of 10 Swiss HNPCC families by genomic sequencing of the hMSH2 and hMLH1 genes. J Med Genet 1995; 32: 909-912.

10. Heinimann K, Scott RJ, Buerstedde J-M, Weber W, Siebold K, Attenhofer M, Mueller HJ and Dobbie Z. Influence of selection criteria on mutation detection in patients with hereditary nonpolyposis colorectal cancer. Cancer 1999; 86: 2512-2518.

11. Wiinen JT, Vasen HFA, Meera Khan P, Zwindermann AH, van der Klift H, Mulder A, Tops C, Moller P and Fodde R. Clinical findings with implications for genetic testing in families with clustering of colorectal cancer. New Engl J Med 1998; 339: 511-518.

12. Syngal S, Fox EA, Li C, Dovidio M, Eng C, Kolodner RD and Garber JE. Interpretation of genetic test results for hereditary nonpolyposis colorectal cancer. Implications for clinical predisposition testing. JAMA 1999; 282: 247-253.

13. Liu B, Parsons R, Papadopoulos N, Nicolaides NC, Lynch HT, Watson P, Jass JR, Dunlop M, Wyllie A, Peltomaki P, de la Chapelle A, Hamilton SR, Vogelstein B and Kinzler KW. Analysis of mismatch repair genes in hereditary nonpolyposis colorectal cancer patients. Nat Med 1996; 2: 169-174.

14. Peltomaki $P$ and Vasen HF. Mutations predisposing to hereditary nonpolyposis colorectal cancer: database and results of a collaborative study. The International Collaborative Group on Hereditary Non Polyposis Colorectal Cancer. Gastroenterology 1997; 113: 1146-1158.

15. Schouten JP, McElgunn CJ, Waaijer R, Zwijnenburg D, Diepvens $F$ and Pals $G$. Relative quantification of 40 nucleic acid sequences by multiplex ligation-dependent probe amplification. Nucleic Acids Res 2002; 30: e57.

16. Miller SA, Dykes DD and Polesky H. A simple salting out procedure for extracting DNA from human nucleated cells. Nucleic Acids Res 1988; 53: 739.

17. Scott RJ, McPhillips M, Meldrum CJ, Fitzgerald PE, Spigelman AD, Tucker K, Kirk J and the Hunter Family Cancer Service. Hereditary non polyposis colorectal cancer in 95 families: differences between mutation positive and mutation negative kindreds. Am J Hum Genet 2001; 68: 118-127.

18. Gille, JJP, Hogervorst FBL, Pals G, Wiinen, JTH, van Schooten RJ, Dommering CJ, Meijer GA, Craanen ME, Nederlof PM, de Jong D, McElgunn CJ, Schouten, JP and Menko FH. Genomic deletions of MSH2 and MLH1 in colorectal cancer families detected by a novel mutation detection approach. Br J Cancer 2002; 87: 892-897.

19. Taylor CF, Charlton RS, Burn J, Sheridan E and Taylor GR. Genomic deletions in $\mathrm{MSH} 2$ or $\mathrm{MLH} 1$ are a frequent cause of hereditary non-polyposis colorectal cancer: identification of novel and recurrent deletions by MLPA. Hum Mutat 2003; 22: 428-433.

20. Charbonnier F, Raux G, Wang Q, Drouot N, Cordier F, Limacher JM, Saurin JC, Puisieux A, Olschwang $S$ and Frebourg T. Detection of exon deletions and duplications of the mismatch repair genes in hereditary nonpolyposis colorectal cancer families using multiplex polymerase chain reaction of short fluorescent fragments. Cancer Res 2000; 60: 2760-2763.

21. Bunyan DJ, Eccles DM, Sillibourne J, Wilkins E, Thomas NS, Shea-Simonds J, Duncan PJ, Curtis CE, Robinson DO, Harvey JF and Cross NC. Dosage analysis of cancer predisposition genes by multiplex ligation-dependent probe amplification. Br J Cancer 2004; 91: 1155-1159. 